\title{
Cardiometabolic risk factors among patients with tuberculosis attending tuberculosis treatment centers in Nepal
}

Indra Prasad Poudyal ${ }^{1 \dagger}$, Pratik Khanal $^{1{ }^{*}+}$ (D), Shiva Raj Mishra ${ }^{2,3}$, Milan Malla $^{4}$, Prakash Poudel ${ }^{1}$, Raj Kumar Jha ${ }^{1}$, Anil Phuyal ${ }^{1}$, Abiral Barakoti ${ }^{4}$ and Bipin Adhikari $^{5}$

\begin{abstract}
Background: The co-morbidity of cardiometabolic diseases in patients with Tuberculosis adds a significant burden in current health systems in developing countries including Nepal. The main objective of this study was to explore cardiometabolic risk factors among patients with Tuberculosis.

Methods: This was a cross-sectional study conducted among patients with tuberculosis in 12 tuberculosis treatment centers from eight districts of Nepal between May and July 2017. Interviews with participants were conducted using a structured questionnaire and were supplemented by anthropometric measurements and on-site blood glucose tests. Data were analyzed using descriptive and inferential statistics.

Results: Among 221 study participants, 138 (62.4\%) had new smear-positive pulmonary tuberculosis, 24 (10.9\%) had new smear-negative pulmonary tuberculosis and 34 (15.4\%) had new extra- pulmonary tuberculosis. Overall, 43.1\% of the patients with tuberculosis had at least one cardiometabolic risk factor. The prevalence of at least one cardiometabolic risk factor was more in male than female (47.8\% versus $33.8 \%)$. Prevalence of tobacco (18.9\% versus $4.8 \%)$, and alcohol (12.6\% versus $6.5 \%)$ use was proportionately higher in male compared to female. The prevalence of hypertension (17\% vs. $21 \%)$ and obesity (11.9\% vs. $12.9 \%)$ was lower in male compared to females. Female $(A O R=0.47 ; C l: 0.23-0.94)$, those from Gandaki Province $(A O R=0.32 ; C l: 0.13-0.79)$ and literate $(A O R=0.49 ; C l: 0.25-$ $0.96)$ had reduced risk of cardiometabolic disease risk factors.

Conclusions: This study highlights the role of gender and socio-demographic characteristics associated with the risk of cardiometabolic diseases in patients with Tuberculosis. The findings from this study can guide medical practitioners and policy makers to consider clinical suspicion, diagnosis and treatment. National treatment guideline can benefit by integrating the management of non-communicable diseases in Tuberculosis treatment centers.
\end{abstract}

Keywords: Tuberculosis, Cardiometabolic risk factors, Non-communicable diseases

\footnotetext{
* Correspondence: pratikkhanal@iom.edu.np

${ }^{+}$Indra Prasad Poudyal and Pratik Khanal equally contributing first authors 'Institute of Medicine, Tribhuvan University, Maharajgunj, Kathmandu, Nepal

Full list of author information is available at the end of the article
}

C C The Author(s). 2020 Open Access This article is licensed under a Creative Commons Attribution 4.0 International License, which permits use, sharing, adaptation, distribution and reproduction in any medium or format, as long as you give appropriate credit to the original author(s) and the source, provide a link to the Creative Commons licence, and indicate if changes were made. The images or other third party material in this article are included in the article's Creative Commons licence, unless indicated otherwise in a credit line to the material. If material is not included in the article's Creative Commons licence and your intended use is not permitted by statutory regulation or exceeds the permitted use, you will need to obtain permission directly from the copyright holder. To view a copy of this licence, visit http://creativecommons.org/licenses/by/4.0/. The Creative Commons Public Domain Dedication waiver (http://creativecommons.org/publicdomain/zero/1.0/) applies to the data made available in this article, unless otherwise stated in a credit line to the data. 


\section{Background}

Tuberculosis (TB) constitutes a top ten causes of mortality globally and resulted in 1.49 million deaths in 2018 [1]. Low and middle-income countries (LMICs) with poor universal health coverage share a disproportionate burden of morbidity and mortality due to TB despite the availability of effective anti-tubercular therapy [1,2]. The highest incidence (2/3rd of the global burden) of new TB cases was reported from South East Asia and the Western Pacific region followed by the African region, which shared a fourth of the global incidence. It is estimated that $95 \%$ of all TB cases and $98 \%$ of all TB deaths occur in South East Asia and Africa [2]. Various factors synergize the burden of morbidity and mortality related to $\mathrm{TB}$ in developing countries that includes poverty, poor public health system, and co-morbidities [3]. Thus, $\mathrm{TB}$ continues to be a persisting challenge in global health [4].

Among an estimated 10 million new TB cases worldwide in 2018, 5.7 million (57\%) were found in men, 3.2 million (32\%) in women and 1.1 million (11\%) in children [5]. In Nepal, almost half of the total population (45\%) is infected with TB and the most affected population (60\%) is productive age group (18-45 years). Annually, 44,000 people develop active TB, and half of which is Pulmonary TB with around 7000 deaths every year [6].

Together with the burden of TB [7], developing countries suffer from an added burden due to the rising epidemic of non-communicable diseases (NCDs) mainly cardiovascular diseases (CVDs). The CVDs are caused by a combination of cardiometabolic risk factors such as tobacco use, physical inactivity, cholesterol, diabetes, obesity and hypertension $[8,9]$. In Nepal, the epidemiological shift has transformed the burden of diseases from communicable to NCDs; the latter contribute to around two-thirds of mortality [10]. The CVDs and its risk factors are prominent in Nepal [11-14]. According to Nepal's Global Burden of Disease Report 2017, Ischemic Heart Disease is the topmost cause of death while cerebrovascular hemorrhage is the fifth major cause of deaths [10]. Studies have shown that population from rural communities in Nepal have inadequate knowledge, attitude and behavior related to cardiovascular health; and are also at equal risk of CVDs as their urban counterparts [12-15]. Besides, the health system readiness for the management of CVDs and other NCDs is suboptimal in Nepal [10, 16-18].

While there are few studies conducted on cardiometabolic risk factors among migrants [19], adult population $[20,21]$ and people living with HIV [22] in Nepal and other developing countries, we could not find any studies on TB patients. The consequence of diabetes, hypertension as well as other cardiometabolic risk factors among patients with TB is under-appreciated. The dearth of evidence has further affected the coordination between TB and NCD control program in Nepal. This study aimed to explore the prevalence of cardiometabolic risk factors among patients with $\mathrm{TB}$ attending DOTS centers of Nepal.

\section{Methods}

\section{Study design and study setting}

This was a facility-based cross-sectional study conducted in $12 \mathrm{~TB}$ centers (DOTS centers) in eight out of 77 districts of Nepal between May and July 2017. The study districts were Morang in Province 1, Dhading in Province 3, Baglung and Tanahaun in Gandaki province, Rolpa in Province 5 and Kailali, Dadeldhura and Doti in Sudurpaschim province. These districts and DOTS centers were purposively selected to ensure inclusion of the urban and non-urban settings of the country. All the patients visiting the treatment centers during the data collection period were recruited for the study purpose.

A total of 238 patients with TB visiting DOTS centers for anti-tubercular therapy during the study period and meeting the eligibility criteria participated in this study. The participants were selected from DOTS clinics of Primary Health Centers (PHCs) and government hospitals of the country. The inclusion criteria for the participants included: (1) aged 15 years and above; (2) newly diagnosed TB or currently under anti-tubercular medication; and (3) those willing to give written informed consent to participate in the study. Pregnant women and lactating mothers were excluded from the study considering associated gestational diabetes mellitus.

\section{Data collection measures}

Patients were interviewed at the DOTS clinic through a structured questionnaire by paramedics or medical officers who were trained to fill the questionnaires. Information about socio-demographic and behavioral characteristics was obtained through interviewing study participants while information on TB category was collected from the patient card. Data on anthropometric measurements and blood pressure assessment were collected using the standard method as described in the WHO STEPS survey [23]. Random blood sugar level was measured in the laboratory by Glucose oxidase- peroxidase method for undiagnosed cases and the value of $200 \mathrm{mg} / \mathrm{dl}$ or more for diabetes and $140 \mathrm{mg} / \mathrm{dl}$ or more for pre-diabetes as recommended by the American Diabetes Association (ADA) [24]. Current tobacco use was described as those who have used smoked or consumed smokeless tobacco within 30 days while current alcohol use was described as those who have at least drank once in the past 30 days. Although cholesterol level is an important cardiometabolic risk factor, lipid profile test was 
not performed in this study because such tests were not available at the primary health care settings.

The questionnaire for data collection was developed based on an extensive literature review. Questionnaire related to socio-demographic characteristics was adapted from Nepal Demographic Health Survey 2016 [25] while information related to behavioral, clinical and anthropometric characteristics was based on the WHO STEPS survey [23].

\section{Study variables}

Socio-demographic variables included data on age, sex, ethnicity, geographical location, educational status and occupation. Behavioral variables included current alcohol use and current tobacco use. Clinical variables included diabetes status, hypertension status and prevalence of HIV/AIDS. Anthropometric variables included measurement of Body Mass Index (BMI). The hypertension status has been presented using both American Heart Association (AHA) and the Joint National Committee for hypertension (JNC) criteria.

For inferential analysis, the prevalence of at least one cardiometabolic risk factor was the dependent variable and all other variables were considered as independent variables. In this study, the presence of any risk factors such as alcohol use, tobacco use, diabetes, and hypertension based on the JNC criteria; and overweight/obesity was considered as the presence of cardiometabolic risk factors.

\section{Data management}

Data were entered in EpiData Version 3.1 and was analyzed using IBM SPSS version 20. Continuous variables were summarized as mean with standard deviation (SD). Categorical variables were expressed as frequencies and percentages and Chi-squared test was performed to compare the proportions. A logistic regression analysis was used to explore the association between sociodemographic variables (independent variables) with the presence of at least one cardiometabolic risk factor (dependent variable). Both unadjusted and adjusted odds ratio (AOR) were analyzed. A significant statistical association were considered when $p$ values were $<0.05$ with 95\% Confidence Interval (CI).

\section{Results}

A total of 238 patients with TB participated in the study. Among them, 221 participants with complete information were retained in the analysis.

\section{Treatment category of patients with TB}

Among the study participants, $62.4 \%(138 / 221)$ had new smear-positive pulmonary TB, $10.9 \%(24 / 221)$ had new smear-negative pulmonary TB and $15.4 \%(34 / 221)$ had new extra-pulmonary TB. The proportion of relapse cases, defaulters and those under treatment failure category among the total cases was 9.0\% (20/221), 1.8\% (4/ $221)$ and $0.5 \%(1 / 221)$ respectively (Table 1$)$.

\section{Socio-demographic characteristics}

The mean age of the participants $( \pm$ SD) was $45.19 \pm$ 17.33 years. In this study, $71.9 \%$ of the study participants were male, $30.8 \%$ were illiterate and $48.9 \%$ were engaged in agriculture as their primary occupation. Major proportion of participants belonged to the Janajati ethnic group (41.6\%) followed by Brahmin/Chhetri (32.1\%) (Table 2).

\section{Behavioral and clinical characteristics}

The proportion of current tobacco and alcohol use among the study participants was $14.9 \%(33 / 221)$ and $10.9 \%(24 / 221)$ respectively. The mean BMI of the participants $( \pm \mathrm{SD})$ was $19.88 \pm 4.13 \mathrm{~kg} / \mathrm{m}^{2}$ with $43.0 \%$ underweight, $9.9 \%$ overweight and $2.3 \%$ obese (Table 3 ). The patient report showed that $3.6 \%(8 / 221)$ of the patients with TB had HIV. The proportion of pre-diabetics was $15.8 \%(35 / 221)$ and diabetics were $6.3 \%(14 / 221)$ (Table 3). The mean blood glucose of the participants $( \pm$ SD) was $114 \pm 46.13 \mathrm{mg} / \mathrm{dl}$.

The mean systolic and diastolic blood pressure $( \pm \mathrm{SD})$ was $112.5 \pm 18.1 \mathrm{mmHg}$ and $72.2 \pm 11.8 \mathrm{mmHg}$ respectively. The prevalence of hypertension according to the AHA classification was $37.1 \%(82 / 221)$ and according to the JNC classification was $18.2 \%(40 / 221)$. Among the study participants, $5 \%(11 / 221)$ were under the antihypertensive medication and 5\% (11/221) had positive first-degree family history for hypertension (Table 3).

Among those who were under anti-hypertensive medications, $72.7 \%(8 / 11)$ had uncontrolled blood pressure according to AHA classification while $63.6 \%$ (7/11) had uncontrolled blood pressure according to JNC classification (Data not shown).

\section{Cardiometabolic risk factors among patients with TB}

Overall, 43.1\% (97/221) of the patients with TB had at least one cardiometabolic risk factor. The prevalence of at least one cardiometabolic risk factor was more in male than female (47.8\% versus $33.8 \%$ ). The proportion

Table 1 Tuberculosis category of the study participants $(n=221)$

\begin{tabular}{lll}
\hline TB status & Frequency & Percentage \\
\hline New smear Positive Pulmonary TB & 138 & 62.4 \\
New smear Negative Pulmonary TB & 24 & 10.9 \\
New Extra Pulmonary TB & 34 & 15.4 \\
Relapse & 20 & 9.0 \\
Treatment failure & 1 & 0.5 \\
Defaulter & 4 & 1.8 \\
\hline
\end{tabular}


Table 2 Socio-demographic and behavioral characteristics and comorbidities among patients with TB $(n=221)$

\begin{tabular}{|c|c|c|}
\hline Variables & Frequency & $\begin{array}{l}\text { Percentage } \\
\text { (\%) }\end{array}$ \\
\hline \multicolumn{3}{|l|}{ Socio-demographic variables } \\
\hline \multicolumn{3}{|l|}{ Age } \\
\hline Less than 20 & 12 & 5.4 \\
\hline $20-39$ & 74 & 33.5 \\
\hline $40-59$ & 81 & 36.7 \\
\hline 60 and above & 54 & 24.4 \\
\hline \multicolumn{3}{|l|}{ Sex } \\
\hline Male & 159 & 71.9 \\
\hline Female & 62 & 28.1 \\
\hline \multicolumn{3}{|l|}{ Ethnicity } \\
\hline Janajati & 92 & 41.6 \\
\hline Brahmin/Chhetri & 71 & 32.1 \\
\hline Dalit & 40 & 18.1 \\
\hline Others (Madheshi, Muslim, Thakuri, Sanyasi) & 18 & 8.2 \\
\hline \multicolumn{3}{|l|}{ Education level } \\
\hline Illiterate & 68 & 30.8 \\
\hline Informal & 39 & 17.6 \\
\hline Primary & 32 & 14.5 \\
\hline Secondary & 55 & 24.9 \\
\hline Higher secondary and above & 27 & 12.2 \\
\hline \multicolumn{3}{|l|}{ Occupation } \\
\hline Agriculture & 108 & 48.9 \\
\hline Unskilled manual & 54 & 24.4 \\
\hline Skilled manual (Professional, technical, clerical) & 40 & 18.1 \\
\hline Sales and services & 19 & 8.6 \\
\hline \multicolumn{3}{|l|}{ Province } \\
\hline One & 45 & 20.4 \\
\hline Three and Five & 35 & 15.8 \\
\hline Gandaki & 54 & 24.4 \\
\hline Sudurpaschim & 87 & 39.4 \\
\hline
\end{tabular}

of patients with TB currently using tobacco, alcohol and having diabetes was higher in males than females while the proportion was higher in females as compared to males for hypertension and being overweight or obese (Table 4). While examining the factors associated with the prevalence of at least one cardiometabolic risk factor, those from Gandaki province ( $\mathrm{AOR}=0.32$; $\mathrm{CI}$ : 0.13-0.79) had lower odds as compared to province one. Female $(\mathrm{AOR}=0.47$; CI: $0.23-$ 0.94 ) and literate ( $\mathrm{AOR}=0.49 ; \mathrm{CI}: 0.25-0.96)$ study participants had a lower chance of having cardiometabolic risk factor as compared to male and illiterate study participants (Table 5).

\section{Discussion}

\section{Overall findings}

This study identified significant factors affecting the risk of cardiometabolic diseases in patients with TB. Our study findings showed that $43.1 \%$ of patients with TB had at least one cardiometabolic risk factor and males were more at risk than females including the behaviors related to consumption of tobacco, and alcohol. Nevertheless, the proportion of hypertension and obesity status was higher in females compared to males. Sex, geographic location and patients' education level were significantly associated with the risk of cardiometabolic diseases. 
Table 3 Behavioral and clinical characteristics among patients with TB $(n=221)$

\begin{tabular}{|c|c|c|}
\hline Variables & Frequency & $\begin{array}{l}\text { Percentage } \\
(\%) \\
\end{array}$ \\
\hline \multicolumn{3}{|c|}{ Anthropometric and Behavioral characteristics } \\
\hline \multicolumn{3}{|c|}{$\mathrm{BMI}\left(\mathrm{kg} / \mathrm{m}^{2}\right)$} \\
\hline Too thin for height $(<18.5)$ & 95 & 43.0 \\
\hline Normal (18.5-24.9) & 99 & 44.8 \\
\hline Overweight (24.9-29.9) & 22 & 9.9 \\
\hline Obese (> 30) & 5 & 2.3 \\
\hline \multicolumn{3}{|l|}{ Tobacco use } \\
\hline Current & 33 & 14.9 \\
\hline Past & 119 & 53.8 \\
\hline Never & 69 & 31.2 \\
\hline \multicolumn{3}{|l|}{ Alcohol use } \\
\hline Current & 24 & 10.9 \\
\hline Past & 123 & 55.7 \\
\hline Never & 74 & 33.5 \\
\hline \multicolumn{3}{|l|}{ Clinical characteristics } \\
\hline \multicolumn{3}{|l|}{ HIV } \\
\hline Positive & 8 & 3.6 \\
\hline Negative & 213 & 96.4 \\
\hline \multicolumn{3}{|l|}{ Diabetic mellitus ${ }^{\mathrm{a}}$ ( $\geq 140 \mathrm{mg} / \mathrm{dl}$ ) } \\
\hline Yes & 35 & 15.8 \\
\hline No & 186 & 84.2 \\
\hline \multicolumn{3}{|l|}{ Diabetes mellitus ( $\geq 200 \mathrm{mg} / \mathrm{dl}$ ) } \\
\hline Yes & 14 & 6.3 \\
\hline No & 207 & 93.7 \\
\hline \multicolumn{3}{|l|}{ Hypertension (JNC $\left.{ }^{b}\right)$} \\
\hline Normal & 123 & 55.7 \\
\hline Pre-hypertension & 58 & 26.2 \\
\hline Stage I Hypertension & 26 & 11.8 \\
\hline Stage II Hypertension & 3 & 1.4 \\
\hline Hypertensive under medication & 11 & 5.0 \\
\hline \multicolumn{3}{|l|}{ Hypertension $\left(\mathrm{AHA}^{\mathrm{C}}\right)$} \\
\hline Normal & 123 & 55.7 \\
\hline Elevated BP & 16 & 7.2 \\
\hline Stage I Hypertension & 42 & 19.0 \\
\hline Stage II Hypertension & 29 & 13.1 \\
\hline Hypertensive under medication & 11 & 5.0 \\
\hline \multicolumn{3}{|l|}{ Family history of Hypertension } \\
\hline Yes & 11 & 5.0 \\
\hline No & 96 & 43.4 \\
\hline Unknown & 114 & 51.6 \\
\hline
\end{tabular}

ancluding prediabetes

bJNC classification

${ }^{\mathrm{C}} \mathrm{AHA}$ classification

\section{Cardiometabolic risk in males}

The preponderance of males in bearing cardiometabolic risk factors highlights their higher proportion of developing TB and thus cardiometabolic diseases. The predominance of males in developing TB echoes with the global and national reports $[5,6]$ which may partially explain the risk of cardiometabolic diseases among these patients. Nonetheless, the socio-cultural role of males in Nepalese society where their increased exposure to work and occupation, food and life-style related behavior compared to females who may not have similar exposure, further explains the higher risk of cardiometabolic risk factors [19]. One associated factor within this study that sheds light on male's increased risk of cardiometabolic diseases is the higher consumption of tobacco and alcohol more than females [13, 19]. Socio-culturally in Nepal, males are at the forefront of earning money and managing the household expenditure. Availability of cash, together with the cultural benefits due to patriarchy in Nepalese society can further explain the increased leeway for males that conduces the affordability for the consumption of alcohol and tobacco [13]. These high-risk behaviors are further predicated on other factors such as level of education, occupation and the individual motivation towards a healthy lifestyle. The significantly higher odds of having at least one risk to cardiometabolic diseases in male patients with TB further support our argument.

\section{Females, obesity and hypertension}

The proportion of female patients with TB in this study who had a higher risk of developing hypertension and diabetes resonates with the nationally representative survey where females were found to be the vulnerable population in developing cardiometabolic diseases, [26] and can be explained by the socio-cultural entanglements of female's role in Nepalese society. Similar to other South Asian nations, females are often housebound, particularly those who are unemployed or are in poor-socio-economic status, and are found to have higher rates of obesity and cardiometabolic risks than male counterparts [27-29]. Females are culturally repressed in their outdoor activities often because of threats of sexual harassments and violence. Such cultural restrictions are further aggravated by lack of urban green spaces, parks and exercise places conducive for physical exercise in South Asia [30]. Embedded in the patriarchal culture of Nepal [31], females are not only burdened by household chores such as cooking, but they are also vulnerable to delayed and irregular eating. Delayed and irregular eating generally stems from cultural and traditional niceties of serving the male members of the family first. Besides, wasting of cooked food in traditional Nepali family (usually devoid of refrigerator) is 
Table 4 Clustering of cardiometabolic risk factors and their socio-demographic correlates among patients with TB $(n=221)$

\begin{tabular}{|c|c|c|c|c|c|c|}
\hline & Overweight/obesity & Tobacco & Alcohol & Diabetes & Hypertension & $\geq 1$ risk factors \\
\hline Variables & $\mathrm{n}(\%)$ & $n(\%)$ & $\mathrm{n}(\%)$ & $n(\%)$ & $\mathrm{n}(\%)$ & $\mathrm{n}(\%)$ \\
\hline Total ${ }^{a}$ & $27(12.2)$ & $33(14.9)$ & $24(10.9)$ & $14(6.3)$ & $40(18.1)$ & $97(43.1)$ \\
\hline \multicolumn{7}{|l|}{ Male } \\
\hline \multicolumn{7}{|l|}{ Age } \\
\hline Less than 20 & $0(0)$ & $0(0)$ & $0(0)$ & $0(0)$ & $0(0)$ & $0(0)$ \\
\hline 20-39 & $6(31.6)$ & $7(23.3)$ & $7(35.0)$ & $1(8.3)$ & $7(25.9)$ & $22(28.9)$ \\
\hline $40-59$ & $12(63.1)$ & $14(46.7)$ & $5(25.0)$ & $3(25.0)$ & $14(51.9)$ & $32(42.2)$ \\
\hline 60 and above & $1(5.3)$ & $9(30.0)$ & $8(40.0)$ & $8(66.7)$ & $6(22.2)$ & $22(28.9)$ \\
\hline \multicolumn{7}{|l|}{ Ethnicity } \\
\hline Janajati & $8(42.1)$ & $8(26.7)$ & $6(30.0)$ & $6(50.0)$ & $8(29.6)$ & $27(35.6)$ \\
\hline Brahmin/Chhetri & $6(31.6)$ & $12(40.0)$ & $6(30.0)$ & $3(25.0)$ & $8(29.6)$ & 27 (35.6) \\
\hline Dalit & $3(15.8)$ & $6(20.0)$ & $6(30.0)$ & $2(16.7)$ & $9(33.3)$ & $15(19.7)$ \\
\hline Others & $2(10.5)$ & $3(13.3)$ & $2(10.0)$ & $1(8.3)$ & $2(7.5)$ & $7(9.1)$ \\
\hline \multicolumn{7}{|l|}{ Education level } \\
\hline Illiterate & $2(10.5)$ & $15(50.0)$ & $13(65.0)$ & $6(50.0)$ & $11(40.7)$ & $28(36.8)$ \\
\hline Informal & $6(31.6)$ & $6(20.0)$ & $1(5.0)$ & $2(16.7)$ & $7(25.9)$ & 15 (19.7) \\
\hline Primary & $3(15.7)$ & $4(13.3)$ & $1(5.0)$ & $1(8.3)$ & $1(3.8)$ & $10(13.2)$ \\
\hline Secondary & $4(21.1)$ & $4(13.3)$ & $5(25.0)$ & $2(16.7)$ & $5(18.5)$ & $14(18.4)$ \\
\hline Higher secondary and above & $4(21.1)$ & $1(3.4)$ & $0(0)$ & $1(8.3)$ & $3(11.1)$ & $9(11.9)$ \\
\hline \multicolumn{7}{|l|}{ Occupation } \\
\hline Agriculture & $7(36.8)$ & $17(56.7)$ & $13(65.0)$ & $10(83.4)$ & $12(44.4)$ & $41(53.9)$ \\
\hline Unskilled manual & $5(26.3)$ & $5(16.7)$ & $4(20.0)$ & $1(8.3)$ & $6(22.2)$ & 15 (19.8) \\
\hline Skilled manual & $4(21.1)$ & $4(13.3)$ & $1(5.0)$ & $1(8.3)$ & $5(18.6)$ & $11(14.5)$ \\
\hline Sales and services & $3(15.8)$ & $4(13.3)$ & $2(10.0)$ & $0(0)$ & $4(14.8)$ & $9(11.8)$ \\
\hline \multicolumn{7}{|l|}{ Province } \\
\hline One & $5(26.3)$ & $7(23.3)$ & $4(20.0)$ & $1(8.3)$ & $9(33.3)$ & $16(21.1)$ \\
\hline Three and Five & $1(5.3)$ & $7(23.3)$ & $7(35.0)$ & $2(16.7)$ & $3(11.1)$ & $13(17.1)$ \\
\hline Gandaki & $8(42.1)$ & $4(13.3)$ & $1(5.0)$ & $1(8.3)$ & $6(22.3)$ & $14(18.4)$ \\
\hline Sudurpaschim & $5(26.3)$ & $12(40.1)$ & $8(40.0)$ & $8(66.7)$ & $9(33.3)$ & $33(43.4)$ \\
\hline Male total $^{\mathrm{a}}$ & 19 (11.9) & 30 (18.9) & $20(12.6)$ & $12(7.5)$ & $27(17.0)$ & $76(47.8)$ \\
\hline \multicolumn{7}{|l|}{ Female } \\
\hline \multicolumn{7}{|l|}{ Age } \\
\hline Less than 20 & $0(0)$ & $0(0)$ & $0(0)$ & $0(0)$ & $0(0)$ & $0(0)$ \\
\hline $20-39$ & $5(62.5)$ & $0(0)$ & $1(25.0)$ & $0(0)$ & $4(30.8)$ & $7(33.3)$ \\
\hline $40-59$ & $2(25.0)$ & $3(100.0)$ & $2(50.0)$ & $1(50.0)$ & $6(46.1)$ & $10(47.6)$ \\
\hline 60 and above & $1(12.5)$ & $0(0)$ & $1(25.0)$ & $1(50.0)$ & $3(23.1)$ & $4(19.1)$ \\
\hline \multicolumn{7}{|l|}{ Ethnicity } \\
\hline Janajati & $5(62.5)$ & $1(33.3)$ & $2(50.0)$ & $1(50.0)$ & $7(53.8)$ & $10(47.6)$ \\
\hline Brahmin/Chhetri & $2(25.0)$ & $0(0)$ & $0(0)$ & $0(0)$ & $3(23.1)$ & $5(23.8)$ \\
\hline Dalit & $1(12.5)$ & $2(66.7)$ & $2(50.0)$ & $1(50.0)$ & $3(23.1)$ & $6(28.6)$ \\
\hline Others & $0(0)$ & $0(0)$ & $0(0)$ & $0(0)$ & $0(0)$ & $0(0)$ \\
\hline \multicolumn{7}{|l|}{ Education level } \\
\hline Illiterate & $2(25.0)$ & $3(100)$ & $4(100.0)$ & $2(100.0)$ & $6(46.2)$ & $12(57.2)$ \\
\hline Informal & $2(25.0)$ & $0(0)$ & $0(0)$ & $0(0)$ & $4(30.8)$ & $4(19.0)$ \\
\hline
\end{tabular}


Table 4 Clustering of cardiometabolic risk factors and their socio-demographic correlates among patients with TB $(n=221)$ (Continued)

\begin{tabular}{|c|c|c|c|c|c|c|}
\hline & Overweight/obesity & Tobacco & Alcohol & Diabetes & Hypertension & $\geq 1$ risk factors \\
\hline Primary & $0(0)$ & $0(0)$ & $0(0)$ & $0(0)$ & $0(0)$ & $0(0)$ \\
\hline Secondary & $3(37.5)$ & $0(0)$ & $0(0)$ & $0(0)$ & $3(23.0)$ & $4(19.0)$ \\
\hline Higher secondary and above & $1(12.5)$ & $0(0)$ & $0(0)$ & $0(0)$ & $0(0)$ & $1(4.8)$ \\
\hline \multicolumn{7}{|l|}{ Occupation } \\
\hline Agriculture & $4(50.0)$ & $2(66.7)$ & $3(75.0)$ & $1(50.0)$ & $11(84.6)$ & $13(61.8)$ \\
\hline Unskilled manual & $3(37.5)$ & $1(33.3)$ & $1(25.0)$ & $1(50.0)$ & $1(7.7)$ & $6(28.6)$ \\
\hline Skilled manual & $1(12.5)$ & $0(0)$ & $0(0)$ & $0(0)$ & $0(0)$ & $1(4.8)$ \\
\hline Sales and services & $0(0)$ & $0(0)$ & $0(0)$ & $0(0)$ & $1(7.7)$ & $1(4.8)$ \\
\hline \multicolumn{7}{|l|}{ Provinces } \\
\hline One & $4(50.0)$ & $2(66.7)$ & $3(75.0)$ & $0(0)$ & $5(38.5)$ & $9(42.9)$ \\
\hline Three and Five & $2(25.0)$ & $0(0)$ & $0(0)$ & $1(50.0)$ & $1(7.7)$ & $3(14.3)$ \\
\hline Gandaki & $1(12.5)$ & $0(0)$ & $0(0)$ & $0(0)$ & $2(5.3)$ & $2(9.5)$ \\
\hline Sudurpaschim & $1(12.5)$ & $1(33.3)$ & $1(25.0)$ & $1(50.0)$ & $5(38.5)$ & $7(33.3)$ \\
\hline Female total $^{\mathrm{a}}$ & $8(12.9)$ & $3(4.8)$ & $4(6.5)$ & $2(3.2)$ & $13(21.0)$ & 21 (33.9) \\
\hline
\end{tabular}

$a_{\text {total }} \mathrm{n}(\%)$ of having individual with $\geq 1$ risk factors with and without disaggregation by sex

Table 5 Factors associated with at least one cardiometabolic risk factor $(n=221)$

\begin{tabular}{|c|c|c|c|}
\hline Variables & $\begin{array}{l}\geq 1 \text { risk factors } \\
\mathrm{n}(\%)\end{array}$ & Unadjusted OR (95\% CI) & $\begin{array}{l}\text { Adjusted OR } \\
(95 \% \mathrm{Cl})\end{array}$ \\
\hline \multicolumn{4}{|l|}{ Age } \\
\hline Less than 40 & $29(29.9)$ & Ref & Ref \\
\hline 40 and above & $68(70.1)$ & $2.00(1.14-3.49)^{*}$ & $1.49(0.77-2.90)$ \\
\hline \multicolumn{4}{|l|}{ Sex } \\
\hline Male & $76(78.4)$ & Ref & Ref \\
\hline Female & $21(21.6)$ & $0.56(0.34-1.03)$ & $0.47(0.23-0.94)^{*}$ \\
\hline \multicolumn{4}{|l|}{ Ethnicity } \\
\hline Dalit & $21(21.6)$ & Ref & Ref \\
\hline Janajati & $37(38.1)$ & $0.61(0.29-1.29)$ & $0.56(0.25-1.27)$ \\
\hline Brahmin/Chhetri & $32(33.0)$ & $0.74(0.34-1.62)$ & $0.72(0.31-1.68)$ \\
\hline Others & $7(7.3)$ & $0.58(0.19-1.79)$ & $0.37(0.11-1.26)$ \\
\hline \multicolumn{4}{|l|}{ Education level } \\
\hline Illiterate & $40(41.2)$ & Ref & Ref \\
\hline Literate & $57(58.8)$ & $0.42(0.23-0.75)^{*}$ & $0.49(0.25-0.96)^{*}$ \\
\hline \multicolumn{4}{|l|}{ Occupation } \\
\hline Agriculture & $54(55.7)$ & Ref & Ref \\
\hline Skilled manual & $12(12.4)$ & $0.43(0.20-0.93)^{*}$ & $0.71(0.29-1.71)$ \\
\hline Sales and Service & $10(10.3)$ & $1.11(0.42-2.95)$ & $1.30(0.46-3.70)$ \\
\hline Unskilled manual & $21(21.6)$ & $0.64(0.33-1.24)$ & $0.79(0.38-1.64)$ \\
\hline \multicolumn{4}{|l|}{ Province } \\
\hline One & $25(25.8)$ & Ref & Ref \\
\hline Three and Five & $16(16.5)$ & $0.67(0.28-1.64)$ & $0.52(0.20-1.37)$ \\
\hline Gandaki & $16(16.5)$ & $0.34(0.15-0.77)^{*}$ & $0.32(0.13-0.79)^{*}$ \\
\hline Sudurpaschim & $40(41.2)$ & $0.68(0.33-1.40)$ & $0.62(0.28-1.36)$ \\
\hline
\end{tabular}


considered 'ominous' which can add pressure to the female members to finish the remaining portion of food. The latter can aggravate irregular and overeating. Women in Nepal are also vulnerable to fasting based on religious and cultural practices. The ramifications of delayed, irregular (over and under) eating and fasting are established to increase the risk of developing obesity, diabetes and hypertension [32]. These socio-culturally shaped behaviors contribute to higher prevalence of cardiometabolic risks in females in Nepal. Though female had significantly lower odds of having at least one cardiometabolic risk factor in this study as compared to males, the greater risk of hypertension and overweight/ obesity cannot be neglected.

\section{Socio-demographic factors and cardiometabolic risk}

Other socio-demographic factors that affect higher risk to cardiometabolic diseases are equally important. Although the population from Gandaki province had a lower risk of developing cardiometabolic risk, causal explanations are hard to draw from the geographic location alone. Nevertheless, this may have been due to the socio-demographic characteristics of the population in Gandaki province, such as higher education level, relatively higher affluence, organized urban planning with adequate space for exercise, increased awareness in regards to food and behavior and other socio-ecological factors.

In this study, literate patients with TB showed reduced risk of cardiometabolic diseases and echoes with previous studies from Nepal [29]. Our findings are also consistent with South African study where the risk of cardiometabolic disorders was higher among men, and was lower in those with higher education and socioeconomic status [33]. The fact that higher education, in general, might have led to increased awareness regarding the NCDs such as diabetes and hypertension and thus the personal modification in food and lifestyle related behavior could be one of the mechanisms to explain the finding.

\section{Limitations and further area of research}

This cross-sectional study relied on questionnaire-based survey at 12 DOTS centers across Nepal and the results are largely representative for eight districts in Nepal. Nevertheless, the study being cross-sectional and dependent on quantitative assessment, causal explanations of the association for cardiometabolic risks among TB patients could not be adequately explained. In future, qualitative studies using in-depth interviews and focus group discussions with the patients with TB can yield a rich set of data to explain the associated factors with cardiometabolic diseases in this study. Also, further studies can build to explore how the current DOTS centers can increasingly collaborate in the management of co-morbid cardiometabolic conditions with evidence suggesting that risk factors of death among patients with TB are non-infectious co-morbidities as well as alcohol and substance abuse [34]. As TB and HIV prevalence continues to decline in Nepal, operational and health system research may provide useful insights on how to integrate a major infectious disease, $\mathrm{TB}$ with a rising trend of NCDs.

\section{Conclusion}

Gender, education and geographical location were significantly associated with the occurrence of at least one cardiometabolic risk factor among patients with TB in Nepal. The factors identified in this study can guide medical practitioners and policy makers to consider clinical suspicion, diagnosis and treatment. Revised ТВ treatment guideline can benefit by integrating the management of NCDs in TB treatment centers. The sociocultural entanglements of these factors and the increasing co-morbidity of cardiovascular diseases urge the need for a broader approach of management of life-style related behavior.

\section{Abbreviations \\ AHA: American Heart Association; ADA: American Diabetes Association; AOR: Adjusted Odds Ratio; BMI: Body Mass Index; Cl: 95\% Confidence Interval; DOTS: Directly Observed Treatment Short Course; JNC: Joint National Committee for Hypertension; LMICs: Low income and middle income countries; MDR: Multi-Drug Resistant; PTB: Pulmonary Tuberculosis; NCDs: Non-Communicable Diseases; PHCs: Primary Health Care Centres; SD: Standard Deviation; TB: Tuberculosis; WHO: World Health Organization}

\section{Acknowledgements}

The authors would like to acknowledge all the study participants and the field research team who were involved in the data collection.

\section{Authors' contributions}

IPP, PK and SRM conceived the concept and design of the study. MM, PP, $R K J, A P$ and $A B$ provided inputs to the study protocol and conducted the survey. IPP, PK, SRM and BA wrote the first draft and underwent substantial revision based on the inputs from all other authors. All the authors have read and approved the manuscript.

\section{Funding}

None.

\section{Availability of data and materials}

All data related to this study are included in the manuscript.

\section{Ethics approval and consent to participate}

Ethical approval for this study was provided by the Nepal Health Research Council, Kathmandu, Nepal (Registration number: 55/2017). A written informed consent was obtained from individual participants. For those under 18 years of age, assent was obtained from the study participants and written consent was taken from their caretakers. Confidentiality and anonymity of the participants were ensured by coding the interviews. Study participants were informed clearly about their freedom to opt-out of the study at any point of time without justifying for doing so.

Consent for publication

Not applicable. 


\section{Competing interests}

Authors have no competing interest associated with this paper. Bipin Adhikari is on the editorial board of BMC Public Health.

\section{Author details}

'Institute of Medicine, Tribhuvan University, Maharajgunj, Kathmandu, Nepal. ${ }^{2}$ Nepal Development Society, Bharatpur, Chitwan, Nepal. ${ }^{3}$ Queensland University, Brisbane, Queensland, Australia. ${ }^{4}$ Department of Health Services, Ministry of Health and Population, Kathmandu, Nepal. ${ }^{5}$ Centre for Tropical Medicine and Global Health, Nuffield Department of Medicine, University of Oxford, Oxford, UK.

Received: 31 March 2020 Accepted: 30 August 2020 Published online: 05 September 2020

\section{References}

1. World Health Organization: Global Tuberculosis Report 2019. 2019

2. World Health Organization: Tuberculosis. 2019. Available online at: https:// www.who.int/en/news-room/fact-sheets/detail/tuberculosis (Accessed 16th April, 2019).

3. Marahatta SB, Yadav RK, Giri D, Lama S, Rijal KR, Mishra SR, Shrestha A, Bhattrai PR, Mahato RK, Adhikari B. Barriers in the access, diagnosis and treatment completion for tuberculosis patients in central and western Nepal: a qualitative study among patients, community members and health care workers. PLoS One. 2020;15(1):e0227293. https://doi.org/10.1371/ journal.pone.0227293.

4. Piot P, Greener R, Russell S. Squaring the circle: AIDS, poverty, and human development. PLoS Med. 2007;4(10):1571-5. https://doi.org/10.1371/journal. pmed.0040314.

5. World Health Organization: Global Health Observatory (GHO) data. 2019. Available online at: https://www.who.int/gho/tb/en/ (Accessed onlin 16th April, 2019).

6. National Tuberculosis Center, Ministry of Health, Government of Nepal: National Tuberculosis Program Nepal. 2018. Available online at: https:// nepalntp.gov.np/wp-content/uploads/2018/03/Final-Annual-Report-NTPN-2 018.pdf. Accessed 16 Apr 2019.

7. DoHS. Annual Report 2014/2015. Kathmandu: Department of Health Services; 2015

8. World Health Organization: Global Report on Diabetes. 2016.

9. Cannon CP. Cardiovascular disease and modifiable cardiometabolic risk factors. Clin Cornerstone. 2007:8(3):11-28.

10. Nepal Health Research Council (NHRC) Ministry of Health and Population, (MoHP) and Monitoring Evaluation and Operational Research (MEOR). Nepal Burden of Disease 2017: A Country Report based on the Global Burden of Disease 2017 Study. Kathmandu: NHRC, MoHP and MEOR; 2019.

11. Vaidya A. Prevalence of coronary heart disease in the urban adult males of eastern Nepal: a population-based analytical cross-sectional study. Dharan: BP Koirala Institute of Health Sciences; 2009.

12. Dhungana RR, Devkota S, Khanal MK, Gurung Y, Giri RK, Parajuli RK, Adhikari A, Joshi S, Hada B, Shayami A. Prevalence of cardiovascular health risk behaviors in a remote rural community of Sindhuli district, Nepal. BMC Cardiovasc Disord. 2014;14(1):92. https://doi.org/10.1186/1471-2261-14-92.

13. Dhungana RR, Thapa P, Devkota S, Banik PC, Gurung Y, Mumu SJ, Shayami A, Ali L. Prevalence of cardiovascular disease risk factors: a communitybased cross-sectional study in a peri-urban community of Kathmandu Nepal. Indian Heart J. 2018;70(Suppl 3):S20-7. https://doi.org/10.1016/j.ihj. 2018.03.003.

14. Khanal MK, Ahmed MSAM, Moniruzzaman M, Banik PC, Dhungana RR, Bhandari P, Devkota S, Shayami A. Total cardiovascular risk for next 10 years among rural population of Nepal using WHO/ISH risk prediction chart. BMC Res Notes. 2017;10(1):120. https://doi.org/10.1186/s13104-0172436-9.

15. Vaidya A, Aryal UR, Krettek A. Cardiovascular health knowledge, attitude and practice/behaviour in an urbanising community of Nepal: a populationbased cross-sectional study from Jhaukhel-Duwakot health demographic surveillance site. BMJ Open. 2013;3(10):e002976. https://doi.org/10.1136/ bmjopen-2013-002976.

16. Ghimire U, Shrestha N, Adhikari B, et al. Health system's readiness to provide cardiovascular, diabetes and chronic respiratory disease related services in Nepal: analysis using 2015 health facility survey. BMC Public Health. 2020;20: 1163.
17. Mishra SR, Neupane D, Bhandari PM, Khanal V, Kallestrup P. Burgeoning burden of non-communicable diseases in Nepal: a scoping review. Glob Health. 2015;11(1):32. https://doi.org/10.1186/s12992-015-0119-7.

18. Vaidya A. Capacity building: a missing piece in Nepal's plan for prevention and control of non-communicable diseases. J Kathmandu Med College. 2018;7(4):131-3.

19. Mishra SR, Ghimire S, Joshi C, Gyawali B, Shrestha A, Neupane D, Sharma SR, Pokharel Y, Virani SS. Cardio-metabolic disease risk factors among south Asian labour migrants to the Middle East: a scoping review and policy analysis. Glob Health. 2019;15(1):33. https://doi.org/10.1186/s12992-019-0468-8.

20. Oladapo O, Falase A, Salako L, Sodiq O, Shoyinka K, Adedapo K. A prevalence of cardiometabolic risk factors among a rural Yoruba southwestern Nigerian population: a population-based survey. Cardiovasc J Afr. 2010;21(1):26.

21. Prasad D, Kabir Z, Suganthy J, Dash A, Das B. Appropriate anthropometric indices to identify cardiometabolic risk in south Asians. WHO South East Asia J Public Health. 2013;2(3-4):142-8.

22. Amberbir A, Banda V, Singano V, Matengeni A, Pfaff C, Ismail Z, Allain TJ, Chan AK, Sodhi SK, van Oosterhout JJ. Effect of cardio-metabolic risk factors on all-cause mortality among HIV patients on antiretroviral therapy in Malawi: A prospective cohort study. PLoS One. 2019;14(1):1-11.

23. Aryal KK, Mehata S, Neupane S, Vaidya A, Dhimal M, Dhakal P, Rana S, Bhusal CL, Lohani GR, Paulin FH. The burden and determinants of non communicable diseases risk factors in Nepal: findings from a nationwide STEPS survey. PLoS One. 2015;10(8):1-18.

24. American Diabetes Association. 2. Classification and Diagnosis of Diabetes: <em>Standards of Medical Care in Diabetes-2019</em>. Diabetes Care. 2019;42(Supplement 1):S13-28. https://doi.org/10.2337/dc19-S002.

25. Ministry of Health NNEal. Nepal Demographic Health Survey 2016. Kathmandu: Ministry of Health; 2017.

26. Mehata S, Shrestha N, Mehta RK, Bista B, Pandey AR, Mishra SR. Prevalence of the metabolic syndrome and its determinants among Nepalese adults: findings from a nationally representative cross-sectional study. Sci Rep. 2018;8(1):14995. https://doi.org/10.1038/s41598-018-33177-5.

27. Adhikari B, Mishra SR. Culture and epidemiology of diabetes in South Asia. J Glob Health. 2019;09(02). https://doi.org/10.7189/jogh.09.020301 Available online at http://www.jogh.org/documents/issue201902/jogh-09-020301.pdf (Accessed on 10th August, 2019).

28. Vaidya A, Shakya S, Krettek A. Obesity prevalence in Nepal: public health challenges in a low-income nation during an alarming worldwide trend. Int J Environ Res Public Health. 2010;7(6):2726-44. https://doi.org/10.3390/ ijerph7062726.

29. Sharma SK, Ghimire A, Radhakrishnan J, Thapa L, Shrestha NR, Paudel N, Gurung K, R M, Budathoki A, Baral N et al: Prevalence of hypertension, obesity, diabetes, and metabolic syndrome in Nepal. Int J Hypertens 2011, 2011:821971 DOl: https://doi.org/10.4061/2011/821971.

30. Adhikari B, Pokharel S, Mishra SR. Shrinking urban greenspace and the rise of non-communicable diseases in South Asia: an urgent need for an advocacy. Front Sustainable Cities. 2019;1:5.

31. Marahatta SB, Amatya R, Adhikari S, Giri D, Lama S, Kaehler N, Rijal KR, Marahatta S, Adhikari B. Perceived stigma of leprosy among community members and health care providers in Lalitpur district of Nepal: a qualitative study. PLoS One. 2018;13(12):e0209676. https://doi.org/10.1371/journal.pone. 0209676.

32. Pot GK, Almoosawi S, Stephen AM. Meal irregularity and cardiometabolic consequences: results from observational and intervention studies. Proc Nutr Soc. 2016;75(4):475-86. https://doi.org/10.1017/S0029665116000239.

33. Peltzer K. Tuberculosis non-communicable disease comorbidity and multimorbidity in public primary care patients in South Africa. Afr J Prim Health Care Fam Med. 2018;10(1):e1-6. https://doi.org/10.4102/phcfm.v10i1.1651.

34. Waitt C, Squire S. A systematic review of risk factors for death in adults during and after tuberculosis treatment. Int J Tuberc Lung Dis. 2011;15(7): $871-85$

\section{Publisher's Note}

Springer Nature remains neutral with regard to jurisdictional claims in published maps and institutional affiliations. 